\title{
Drone Filming: Creativity versus Regulations in Autonomous Art Systems. A Case Study.
}

\author{
DR. SHREEPALI PATEL
}

Director, StoryLab Research Institute, Anglia Ruskin University, Cambridge, UK

\begin{abstract}
This article explores the impact of drone regulations on the narrative potential of drone filming. The central focus of this exploration is a Case Study analysis of the production of a multi-screen audio-visual digital installation, The Crossing (Patel, 2016). The Crossing [1], filmed in central London, utilized the use of a heavyweight Unmanned Aerial System (UAS) also known as a drone with a 5-kilogram weight load capacity with the Alexa Mini WCU-4. Combined with the CForce Mini lens control system, the UAS gave unparalleled camera and lens control at extended ranges, providing complete pan, tilt and lens control and allowing dynamic moves in the air. The result was the ability to navigate through spaces to give intimate and playful shots that give the viewer 'alternate' versions of reality that only a machine can provide. Artists, performers and filmmakers are finding new kinds of beauty through automated programming where the drones are not just capturing the story but the machines themselves become the story. However, the operational scope of drones is limited by legal and health and safety regulations, particularly within built up urban environments. These regulations govern the vertical and horizontal distance from objects and people, line of sight, time constraints, weather conditions as well as security implications. Further restrictions include requiring a trained and fully licensed crew with permission from the relevant aviation bodies. This article seeks to answer whether these restrictions limit the creativity of the artist or challenge the creator to consider alternate ways of using these Autonomous Art Systems to inform the aesthetic scope of the captured image. This article will draw on a combination of original filming and broadcast examples to examine how legal and security restrictions on UAS inform the narrative and aesthetic realization of the final art form and subsequent emotional and physical response of the spectator.
\end{abstract}

This article explores the impact of drone regulations on the narrative potential of drone filming. The central focus of this exploration is a Case Study analysis of the production of a multi-screen audio-visual digital installation, The Crossing (Patel, 2016). The Crossing [1], filmed in central London, utilized the use of a heavyweight Unmanned Aerial System (UAS) also known as a drone with a 5-kilogram weight load capacity with the Alexa Mini WCU-4. Combined with the CForce Mini lens control system, the UAS gave unparalleled camera and lens control at extended ranges, providing complete pan, tilt and lens control and allowing dynamic moves in the air. The result was the ability to navigate through spaces to give intimate and playful shots that give the viewer 
'alternate' versions of reality that only a machine can provide. Artists, performers and filmmakers are finding new kinds of beauty through automated programming where the drones are not just capturing the story but the machines themselves become the story. However, the operational scope of drones is limited by legal and health and safety regulations, particularly within built up urban environments. These regulations govern the vertical and horizontal distance from objects and people, line of sight, time constraints, weather conditions as well as security implications. Further restrictions include requiring a trained and fully licensed crew with permission from the relevant aviation bodies. This article seeks to answer whether these restrictions limit the creativity of the artist or challenge the creator to consider alternate ways of using these Autonomous Art Systems to inform the aesthetic scope of the captured image. This article will draw on a combination of original filming and broadcast examples to examine how legal and security restrictions on UAS inform the narrative and aesthetic realization of the final art form and subsequent emotional and physical response of the spectator.

The Crossing is an experimental cross-platform film that explores the story of a young girl trafficked into a multibillion dollar organized industry through the use of a 'lover-boy' technique (where a man seduces then grooms a young girl for trafficking through the promise of love or a better life). Within the film, the young girl's story unfolds through interconnected screens using intense sound design and perspective shifting visuals, including long floating drone shots. The film takes as its starting point the concept of 'hope' and its gradual unfurling reality into an exploitation of trust to perpetuate a $\$ 150$ billion world trade in 21 million people, a third of which are children [2]. The result is an intense and immersive exploration of the destructive consequences of human trafficking through a heightened audio-visual experience.

I designed the project to enable the viewer to experience the disorientating and disturbing world of a trafficked woman through perspective shifting visuals and sound design. We used several creative tools to create this feeling including visual effects, graphics and sound design experienced through individual Bluetooth headphones. Another key element in constructing this world was the movement and speed of the camera, and in particular the UAS.

The UAS, or drone as it's more widely known as, is high on the UK Government agenda in terms of health and safety. The current Civil Aviation Authority (CAA) regulations [3] state that cameraequipped drones should stay within line of sight, maximum height of 400 feet (122metres), 50m away from a person, vehicle, building or structure not owned or controlled by the pilot and should not be flown within $150 \mathrm{~m}$ of a congested area or large group of people. Recently imposed Government regulations mean that unlicensed drone users will be forced to sit safety tests as the number of near misses with planes increases by $60 \%$. Police have been given greater powers to prevent unsafe or criminal use of the machines while new technology could be used to create nofly zones for drones. This followed a near accident in July 2017 by a UAS flying directly over the right wing of an Airbus A319 whilst approaching the landing strip at Gatwick Airport, UK, putting 130 lives at risk according to the UK Airprox Board. However, the government recognized that drones have great potential and are committed to utilizing the full potential of the technology [4]. The government is also working with drone manufacturers on geofencing technology, to produce virtual barriers preventing machines from operating in restricted areas.

We worked with a fully licensed crew to film the drone footage within the film at four specific locations in central London - defined as a congested zone. This article focuses on two specific 
scenes within The Crossing filmed with an UAS, and examines how the legal and security restrictions on UAS inform the narrative and aesthetic realization of the final art form and subsequent emotional and physical response of the spectator. The two scenes were filmed at the following locations, the grounds of St Pancras Old Church, Kings Cross, London and Potters Fields Park, Tower Bridge, London.

The proposed filming at both sites involved filming with an experienced crew with a UAS Operating Safety Case (OSC) of 10m, which allowed the licenced pilot to fly within 10 metres of people and property not under their control. Our film crew included: the director (myself), cinematographer, the pilot (UAS OSC 10m) drone supervisor (maintains the operational, health and safety communication with stewards, crew and CAA), Gimbal operator (controls the movement of the camera) and six stewards. The machine used was a heavyweight $(20 \mathrm{~kg})$ UAS with a 5 kilogram weight load capacity with the Alexa Mini WCU-4. Combined with the CForce Mini lens control system, a MoVI 15 gimbal.

A Health and Safety plan had to be submitted to the CAA for full approval before filming permission was granted. The plan required the date, location and details of the proposed operation, the flight plan, stewarding and consultation plan and finally a risk assessment and method statement.

Our proposed operation involved aerial General Views (GV's) contained within defined boundaries with a $10 \mathrm{~m}$ cordon implemented from the public at all times and 50metres from railway lines. Our pilot held Small UAS licence to fly UAS $7-20 \mathrm{~kg}$ within congested areas. During any flight within a congested area or control zone, the aircraft was legally bound to operate an anti-collision strobe light with a minimum crew of two persons (pilot and spotter/photographer), at a height exceeding 600 feet above ground level at a distance beyond the visual range of the person in charge of the aircraft, or a maximum range of 500 metres. The aircraft could not fly within 10 metres of any person, vessel, vehicle or structure not under the control of the pilot. The aircraft was equipped with a mechanism that would cause the it to land in the event of disruption to or a failure of any of its control systems including the radio link. The pilot was liable for checking the air-worthiness of the machine, the camera was properly secured and that the flight could be safely be made considering the wind and other significant weather conditions. This particular UAS had a wingspan of 01.56 metres operating flights capable of 6-8 minute durations. The flight plans show a flight zone within the red perimeter and flight impact zone, and notification of any public transport areas (e.g. Network rail in the case of the St. Pancras location). All stewards were bound to attend safety briefings led by the pilot and act accordingly. The stewards were appointed on location wearing high visibility clothing and placed at access points for where the public or members of staff may come through the flight zone. Physical barrier tape was used where necessary. All communication occurred via mobile phone and hand visual signalling. The UAS carried a Teradek Bolt 2000 Pro HD downlink for monitoring ground station. If anyone required access or strayed into the flight cordon (public incursions) - then the pilot had to move the UAS away or land until safe to continue. As part of the consultation plan - notifications were made to the Met Police, Camden Film Unit, Adjacent residents and offices, Network Rail and NAS. A generic Risk assessment for Congested Area UAS detailing flight redundancy and aircraft system safety was submitted prior to filming.

The rationale for filming at Potters Field, London close to the Tower Bridge was to capture the financial sector at Bank on the other side of the river to reinforce the black market economy that 
drives trafficking, and to capture this at the 'magic hour' -sunrise. When we arrived there was thick fog and mist. Up until that point we did not know what the weather would give us. Usually that would have caused substantial issues for filming, but drone shots can be much more interesting when the elements give you something much more interesting to play with. Flat, bright light doesn't actually look that beautiful from a drone's perspective, but drama and shadows do. The stewards were placed at key points around the perimeter of agreed location to control movement in and out of the line of sight of the drone. We felt that at that time of the morning there would be very little issue, however, it was the morning after Halloween, and there were some drifters from the festivities from the night before which made for interesting additions to the landscape. The stewards communicated via mobile phone to either hold passer-by's back until we had completed a shot, or to land the drone until movement had stopped. The mist made it really magical. And when the drone was taken up - it offered a new perspective on the landscape. The banking quarter wasn't visible, but the necklace of lights along the boardwalk and on Tower Bridge, provided track lines that the drone could play with and capture. The drone could gently track and drift over the top of the head of our young girl and create a real sense of isolation, foreboding and hyper-reality. It's an extraordinary plane just 400 feet up. A few hours later in the same environment would have been completely different. The legal restrictions on filming forced us to consider very early in the morning at such an iconic location, which a few hours later would have been absolutely packed and filming impossible.

Dziga Vertov's 1923 manifesto, asserts of the camera 'I am the kino-eye, I am the mechanical eye. I, a machine, show you the world as only I can see it'. Vertov's observations continued in his 1929 essay, From Kino-Eye to Radio-Eye, 'Kino-Eye means the conquest of space... the possibility of seeing life processes in any temporal order or at any speed'[5]. Our UAS gave us unparalleled camera and lens control at extended ranges, providing complete pan, tilt and lens control and allowing dynamic moves in the air. The weight the machine holds takes it to a new dimension, enabling beautiful stability with its weight and the use of a higher calibre camera, the Alexa Mini for more impactful material to be shot achieving the quality of ground based cameras, rather than limited to the weight capacity of the lightweight drones. Its Kino-Eye captured beautiful, ethereal and impactful shots. One spectator commented "The movement of the film in relationship to myself made me feel like I was moving through the story" [6].

Our second location examined for this article focuses on the St Pancras Gardens, Kings Cross, a small enclosed park overseen by the Parish of St. Pancras, with a road to one side, hospital to the end and the Kings Cross railway line over its walled borders to the side. We were restricted to filming in the late afternoon after the parishioners had left after the Sunday service. We placed safety notices around the park, and leafleted the nearby residences, hospital and notified National Railway that we would be filming with contact numbers for those that had queries or objected. There were a few visitors walking their dogs in the park, controlled by our human ring fence of stewards. The park was chosen for its proximity to the railway line, an element of the narrative within the story illustrating the journey of our trafficked girl. We were once again open to the elements having filmed in the mist and fog a few hours earlier - we were unsure what the afternoon would bring us, we hoped not rain or wind. We were faced with the autumnal hues of fallen leaves and the afternoon sun slicing through the trees casting dramatic shadows. Here we used the drone to capture the environment, with the propellers of the drone pushing the leaves forward which filmed at 100 frames per second draws the audience into the hypnotic movement of the leaves extending the hyper reality of the narrative. We used the drone to travel from our young isolated 
girl up through the trees, panning and tilting, utilising the full range of the 360 gimble as it moved upwards through the magic of the trees until reaching the top revealed the harsh ugliness of the railway line and the reality of the dirty city she had given up her family for. The grounding stability of the camera, with the drone's extraordinary stabilization allowed these circular movements to swirl seamlessly capturing beautiful floating footage. The movement was similar to that of internal human stabilization - e.g. the way we move our heads or when we move our bodies. In effect, as humans we can see in beautifully smooth cinematic terms rather than an awkward jerkiness. Similarly with drones, there has to be an invisible movement that doesn't disturb the smooth hyperreality of the shot. The more recent UAV's have been developed and adapted to counter the jerkiness and the heaviness of the camera and the gimbal supports the balancing and movement, though this is still subject to weather conditions.

The 'gaze' is a key element within this film. The gaze of our young girl connects, doesn't flinch and draws the spectator to her eyes, her story and to understand the narrative from her perspective. John Berger's considers the spectators gaze as 'voyeuristic' when viewing art or film [7]. The idea of the gaze focuses upon the viewer and their relationship with what they see, we are invited by images to see in a particular way, but we also come to them with already existing relationships to what we see. Duncum [8] suggests that 'this means that considering the gaze is a way in which to understand ourselves as individual and as a society'. The gaze means reflecting on whether the very act of our looking implicates us in a violation of the subject of our gaze and throws a spotlight on us, as viewers and our context. Fundamental to Berger and Duncum's approach is the presumption that while knowledge is integral to vision, the relationship between knowing and seeing is complex and unsettled.

Feedback from a visitor at the Ruskin Gallery, Cambridge exhibition underlined this approach, 'I felt the 'artistic' visual aesthetics played an important role in humanizing the storyteller. They acted as a sort of partial barrier, disallowing me to objectify (de-humanize) her with my pity. This contrasts with the type of images which would accompany this type of story usually in documentary/news reporting online or on TV. It also worked to connect me to her as a 'normal' person', 'someone like me', connecting me to the idea that his can happen to anyone.'... It makes me think about my role as a BYSTANDER. If I know what is happening, why don't I take action?' [9]

To capture this gaze, the pilot flew the drone as close as he reasonably could within the legal limit of $10 \mathrm{~m}$. The aircraft, could not be flown in winds above 15 miles per hour, and the craft we used had dual-redundancy flight control which means if one goes wrong it can be switched to another, and it includes a ballistic parachute etc. to satisfy the CAA that the team had the necessary control to bring the drone down with a control descent from 600 feet to within a $10 \mathrm{~m}$ radius.

I would argue that that the health and safety regulations placed upon the use of UAV's challenge the creators to consider alternate ways of using the drone to inform the aesthetic scope of the captured image, rather than restrict their creativity. Drones can now handle much bigger cameras, which is having a significant impact in terms of how it is used and by whom (e.g. features, drama, commercials, etc.). Cameras such as the Alexa Mini or the Red give unparalleled camera and lens control at extended ranges, providing complete pan, tilt and lens control and allowing dynamic moves in the air. This means that instead of the usual $12 \mathrm{~mm}$ fixed wide lens of the Sony G8 or the Panasonic GH4, which give uninteresting 'factual' looks to film, we are able to experiment with 
different lens combinations that open up numerous possibilities. The very nature of the concept of The Crossing i.e. to create an immersive experience for the spectator provided the drone operators with a much more interesting proposition - i.e. the ability to experiment with the space giving intimate and playful shots which were not defined or constrained by a specific narrative. The UAS is a very different tool to a conventional camera because of its ability to float through the air, operating on different conventions to a jib or a crane that carries a camera. The director's vision combined with the knowledge and skill of an experienced drone operator can produce exciting imagery based upon the communication of the team and how that vision is interpreted via the combined disciplinary expertise. The UAS facilitates working in a space that before the drone goes up, we wouldn't have had access to before, and dependent on the movement and trajectory of travel brings a different perspective on the captured space. The director can integrate the intimacy and the aesthetic, combined with the other elements of the filmmaking process, such as voiceover and sound design. Adam Gee, Commissioning editor, Forbidden Zones [10] emphasizes the role of the soundscape in driving a hyper real perspective on films using drones in particular, particularly within the films he commissioned and combined with voiceovers (similar to The Crossing) can really give you an intimate insight into the narrative layers embedded within the film.

Drone supervisor, Emma Boswell, The Helicopter Girls [11] emphasizes the importance of the recce prior to filming to consider how the drone can 'play' in the environment given the operational scope limited by health and safety regulations, particularly within built up urban environments. When considering the vertical and horizontal distance from objects and people, line of sight, time constraints, weather conditions and security implications - the recce is vital. However, when first entering an environment for filming, the team should consider what can be drawn from the environment rather than just the restrictions. Apart from looking for objects that the drone may fly into - look for foreground objects and what they can reveal. Identify the narrative within the movement of the shot itself. The key is to consider 'how can we play' with the environment and to also be prepared for changes in the weather and environment that will impact on what is captured and how safely.

Drones are still a niche interest but they have reached a mass market tipping point where a drone can be bought quite cheaply and readily on the high street. They have captured the collective imagination because they can enhance the recording of our experiences in the natural world in a way that had never previously been dreamed of without huge expense. This new landscape can give you an extraordinary view of a place that we can't visit - but the machines can, e.g. Postcards from Pripyat, Chernobyl [12]. It can reveal truths that can't be denied and that pictures from the ground cannot. There are many ways of playing with perspective and narrative e.g. Tim Sessler's Balance [13] playing with the contra-zoom and the roll-axis filmed producing shots that enhance the narrative.

The rules and regulations may be seen as constricting creativity, but when operating with a fully licensed pilot and UAS crew, you are able to pioneer flights in congested areas where drones aren't generally able or allowed to go. It does mean a massive undertaking for the pilot who has built the aircraft to record every single detail, right down to the torque on the screws to prove to the CAA that every single point of failure on the aircraft has been addressed. But by working with experienced crew the health and safety regulations can be developed to reduce redundancy from the normal 150 meters right down to $10 \mathrm{~m}$, reducing the safety bubble around the aircraft down to $20 \mathrm{~m}$, which make a lot more things possible. The key to creating innovative, creative visual content 
is knowing what the boundaries are, playing within them and maximising the full potential of these extraordinary machines.

\section{REFERENCES}

[1] Patel, S. (2016) The Crossing available https://vimeo.com/229111705

[2] United National Office on Drugs and Crime: Global Report On Trafficking In Persons Profits and Poverty: The Economics of Forced Labour, International Labour Office, Geneva. Special Action Programme to Combat Forced Labour (SAP-FL) Fundamental Principles and Rights at Work Branch (FPRW) 2014

[3] http://www.caa.co.uk/Consumers/Unmanned-aircraft-and-drones/ (accessed 12/12/17)

[4] Drone Users Will be Forced to Sit Safety Tests, Aviation Minister Baroness Sugg, The Telegraph, 2017 (accessed 12/12/17)

http://www.telegraph.co.uk/news/2017/11/26/drone-users-will-forced-sit-safety-tests-numbernear-misses/

[5] Vertov, D., \& Michelson, Annette. (1995). Kino-eye : The writings of Dziga Vertov.

Berkeley, Ca.: University of California Press.

[6] The Crossing, surround screening, 3Sixty, Ron Cooke Hub, Arts and Humanities Research

Council, Common Ground Event, 2016

http://www.ahrc.ac.uk/newsevents/events/calendar/common-ground/

[7] Berger, John, Blomberg, Sven, Fox, Chris, Dibb, Michael, \& Hollis, Richard. (1972) Ways of seeing (Penguin art and architecture). BBC and Penguin.

[8] Duncum, P. (2010). 7 SEVEN PRINCIPLES for Visual Culture Education. Art Education, 63(1), 6-10.

[9] The Crossing Exhibition, Ruskin Gallery, Cambridge UK https:/www.anglia.ac.uk/arts-lawand-social-sciences/ruskin-gallery/the-crossing

[10] Adam Gee, Commissioning Editor, Drones in Forbidden Zones

http://www.channel4.com/programmes/drones-in-forbidden-zones

[11] http://thehelicoptergirls.com

[12] Postcards from Pripyat, Chernobyl recorded for CBS 60 minutes: Chernobyl: The

Catastrophe that never ended. 2014. Accessed 10/12/17

http://www.cbsnews.com/news/chernobyl-the-catastrophe-that-never-ended/

https://vimeo.com/112681885

[13]Sessler, T (2016) Balance accessed 10/12/17 at https://vimeo.com/163590531

\section{AUTHOR BIO}

Dr Shreepali Patel is Director of StoryLab Research Institute, Cambridge, former BBC Producer/Director, BAFTA award winning filmmaker and co-director of Emmy award winning company Eyeline Films. Her research focuses on existing and emerging audio-visual technologies, multimodal narratives and user experience. https:/www.anglia.ac.uk/storylab 